\title{
The Method of Improving the Corrosive Environment in a Reclaimed-Water Pipe using the SA Method
}

\author{
Myeongsik Kong ${ }^{1}$, Hyundong Lee $\mathrm{e}^{1,2, \dagger}$ and Joonhyung Lee ${ }^{3}$ \\ ${ }^{1}$ Korea Institute of Civil Engineering and Building Technology, Environment and \\ Plant Engineering Research Institute. Daehwa-dong 283, Goyangdae-Ro, Ilsanseo- \\ gu, Goyang-si, Gyeonggi-do, Republic of Korea \\ ${ }^{2}$ Korea University of Science and Technology, Construction and Environment \\ Engineering. 217, Gajeong-ro, Yuseong-gu, Daejeon, Republic of Korea \\ ${ }^{3}$ Korea Institute for Advancement of Technology, Regional Policy Planning Team. \\ Korea Technology Center 305, Teheranno, Gangnam-Gu, Seoul, Republic of Korea \\ mskong@kict.re.kr,hdlee@kict.re.kr,leejh106@kiat.or.kr \\ ${ }^{\dagger}$ : Corresponding author
}

\begin{abstract}
To increase the practical-use value of multi-water-resources, reclaimed water was used as the experimental water because the frequency of reclaimed-water usage has been very high of late. The SA method was then applied to a reclaimed-water pipe as a way of inhibiting its corrosion, and its anticorrosion effect was observed. Corrosion effect by the sacrificial anode method was measured by lab scale experiments, reclaimed water was used as the experimental water, and also tap water was used as a control group. As a result of experiments, efficiency of SA method can be made higher by increasing the amount of SA metal. In addition, anticorrosive effect was not large compared to the reclaimed water condition, and it was determined that efficiency of the SA method increases in a pipeline where high-conductivity water flows. And the corrosive-index (KRWI) trend was not large regardless of the flow time and the degree of corrosion.
\end{abstract}

Keywords: SA method, Reclaimed water, Speed of corrosion, KRWI

\section{Introduction}

The average annual precipitation in Korea is $1,245 \mathrm{~mm}$, which is a relatively greater figure compared to the global average of $880 \mathrm{~mm}$. However, the annual precipitation per person is $2,591 \mathrm{~m}^{3}$, a measly number equivalent to about $1 / 8$ of the global average of $16,635 \mathrm{~m}^{3}$. In addition, although the amount of water resources in South Korea is about 1,300 billion $\mathrm{m}^{3}$ per year, a huge amount of water is lost to evapotranspiration (54.4 billion $\left.\mathrm{m}^{3}\right)$, ground water filling $\left(3.7\right.$ billion $\left.\mathrm{m}^{3}\right)$, and dam water volume $\left(18.8\right.$ billion $\left.\mathrm{m}^{3}\right)$, and flows into the river.sea $\left(52.8\right.$ billion $\left.\mathrm{m}^{3}\right)$; thus, the amount that is actually used is only 33.5 billion $\mathrm{m}^{3}(21 \%)$. Also, since the bulk of precipitation is concentrated during summer due to climatic and seasonal effects and, subsequently, increasing spring and fall droughts, a proper, efficient distribution of water resources has been difficult. To solve this phenomenon of water shortage, various research and technical development to improve water resources and their efficient distribution have been conducted at the national scale. Several solutions, including the one in which multi-sourced water supplies are properly processed and used to supply water according to different purposes, have been proposed. In Korea, 714 million $\mathrm{m}^{3}$ among 6600 million $\mathrm{m}^{3}$ of the total annual amount of processed sewage water are reclaimed, as of late 2008 , which is equivalent to approximately a $10.8 \%$ reuse rate. More than half of it (400 million $\left.\mathrm{m}^{3}, 56 \%\right)$ is utilized as indoors such as water 
for washing, cleaning, and coolant, while the rest $\left(310\right.$ million $\left.\mathrm{m}^{3}, 44 \%\right)$ is utilized outdoors such as water for river maintenance, as well as industrial and agricultural uses.

Until now, most research related to reclaimed water has focused primarily on processing methods. Only recently has there been an effort to investigate the causticity of reclaimed water and to develop an evaluation index, but still almost no research has been conducted in finding ways to suppress corrosion and extend the life span of pipes.

Therefore, this research aims to improve upon the corroded state of reclaimed water pipes by conducting a series of experiments that employ the SA method in the reclaimed water supply pipe networks.

\section{Contents of Research}

\subsection{Experiment Apparatus}

To measure the effects of SA, the research employed 5 loop-systems, each of which consisted of a closed system in which water circulates continuously. Apparatus \#1 was not applied with SA while \#2 through \#4 were applied with varying amounts of SA $(20 \mathrm{~mm}$, $40 \mathrm{~mm}$, and $60 \mathrm{~mm}$, respectively), using reclaimed water for the experiment. Apparatus \#5 applied the same conditions as \#3 except it used tap water.

\subsection{Experiment Materials}

Zinc was utilized as the SA metal in this study. Zinc is a substance that corresponds to the transition metal in the 30th element number. The main uses of zinc are for corrosion resistance plating on iron, for the manufacture of brass (an alloy of copper), and as a battery. The effect of the SA has already been subjected to verification on galvanized steel pipes, but a problem occurred: corrosion progressed rapidly after the consumption of zinc plating. As a result, the use of galvanized steel pipes is now prohibited. The components of high-purity zinc, which was used for plating in the experiment in this study, are shown in Table 1.

Table 1. Composition Proportion of High Purity Zinc

\begin{tabular}{lllllll}
\hline Compounds & Zinc & Lead & Cadmium & Iron & Copper & Tin \\
\hline $\begin{array}{l}\text { Proportion } \\
(\%)\end{array}$ & 99.9968 & 0.0019 & 0.0002 & 0.0005 & 0.0003 & 0.0001 \\
$(\min )$ & $(\max )$ & $(\max )$ & $(\max )$ & $(\max )$ & $(\max )$ \\
\hline
\end{tabular}

To observe the corrosion status, non-plating carbon steel pipe was used as the experimental piping material. For reclaimed-water pipes, various pipes are used, such as PVC, PE, and DCIP, but for the dramatic observation of the corrosion resistance, it was determined that carbon steel is the most suitable experimental material.

Reclaimed water is produced and utilized in some regions, and in this study, I City's reclaimed water was used as the experimental water. The water quality characteristics of I City's reclaimed water are shown in Table 2. The reclaimed water was treated at a sewage facility with the sand filtration, activated carbon filtration, and sodium hypochlorite sterilization processes (Fig. 1). In the experiment using tap water, the tap water supplied by G City was used. The characteristics of the water quality are shown in Table 2. 
Table 2. Characteristics of Water Quality in Reclaimed Water(I city) and Tap Water(G city)

\begin{tabular}{cccc}
\hline Parameter & Unit & \multicolumn{3}{c}{ Value } \\
\hline Turbidity & $\mathrm{NTU}$ & 0.791 & 0.088 \\
Temperature & ${ }^{\circ} \mathrm{C}$ & 26.1 & 25.9 \\
$\mathrm{pH}$ & - & 7.42 & 7.86 \\
$\mathrm{DO}$ & $\mathrm{mg} / \mathrm{L}$ & 4.94 & 4.86 \\
Conductivity & $\mu \mathrm{c} / \mathrm{cm}$ & 3,700 & 177.45 \\
$\mathrm{Alkalinity}_{\mathrm{TOC}}$ & $\mathrm{mg} / \mathrm{L} \mathrm{as} \mathrm{CaCO}$ & 96 & 43 \\
$\mathrm{mg} / \mathrm{L}$ & 2.86 & 1.29 \\
$\mathrm{Cl}^{-}$ & $\mathrm{mg} / \mathrm{L}$ & 105.75 & 1.34 \\
Residual chlorine $_{\mathrm{SO}_{4}{ }^{2-}}$ & $\mathrm{mg} / \mathrm{L}$ & 0.01 & 0.2 \\
Total Hardness & $\mathrm{mg} / \mathrm{L}$ & 6.87 & 12.0 \\
\hline
\end{tabular}

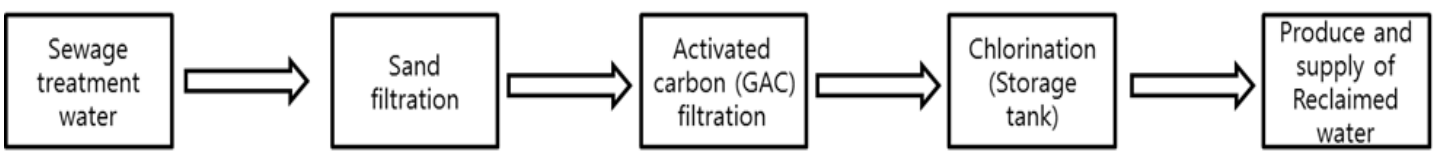

Figure 1. Basic Diagram of Experimental Equipment

\subsection{Experiment Method}

In this study, different amounts of zinc pieces were manufactured to determine the differences in anticorrosion effect according to the amount of zinc piece used (20,40, and $60 \mathrm{~mm}$ ). A carbon steel pipe was installed in all the experimental apparatuses, and the pipes were manufactured in the same way $(100 \mathrm{~mm})$. A picture and the basic diagram of the experimental apparatus are shown in Figure 2, respectively, and the full specifications of the experimental apparatus are shown in Table 3.

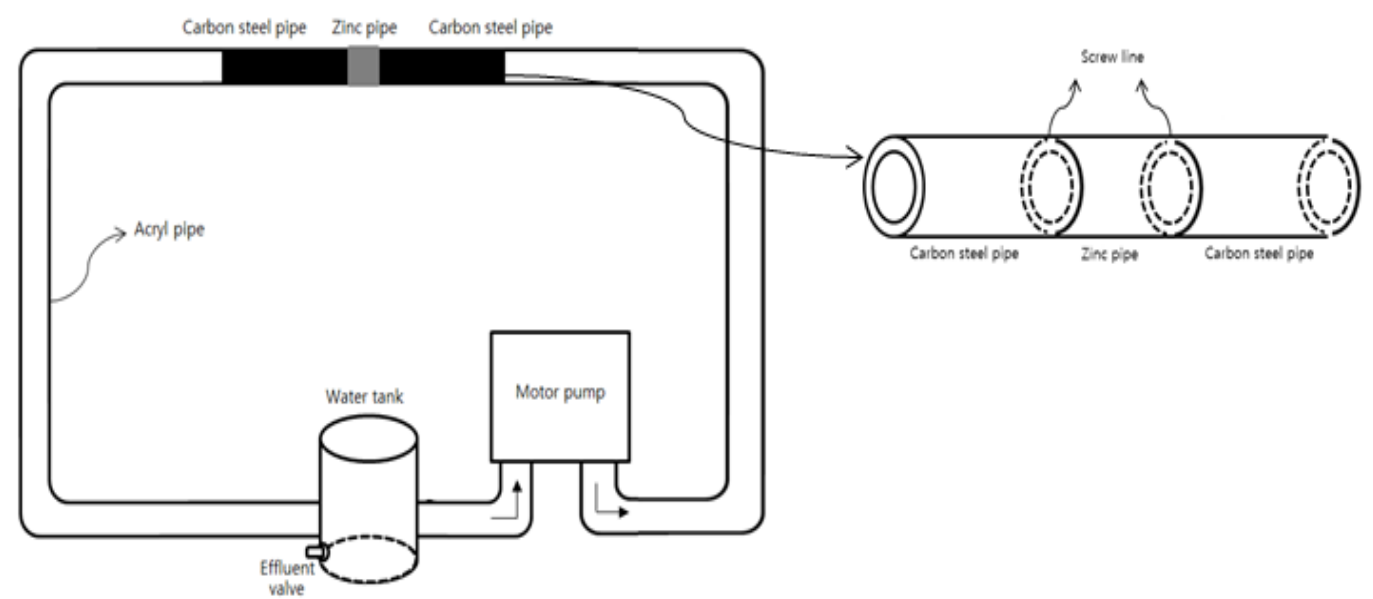

Figure 2. Basic Diagram of Experimental Equipment 
Table 3. Status of Experimental Equipment

\begin{tabular}{|c|c|c|c|c|c|}
\hline Parameter & \multicolumn{5}{|c|}{ Value } \\
\hline Type of experiment & \multicolumn{5}{|c|}{ Close loop system } \\
\hline Equipment size & \multicolumn{5}{|c|}{$800 \mathrm{~mm}(\mathrm{~W}) \times 400 \mathrm{~mm}(\mathrm{H})$} \\
\hline $\begin{array}{l}\text { Size of carbon steel } \\
\text { specimen }\end{array}$ & \multicolumn{5}{|c|}{$100 \mathrm{~mm}$} \\
\hline \multirow{2}{*}{$\begin{array}{l}\text { Size of zinc } \\
\text { specimen }\end{array}$} & No. $1^{*}$ & No.2 & No.3 & No.4 & No.5 \\
\hline & - & $\begin{array}{l}20 \mathrm{~mm} \\
(133.50 \mathrm{~g})\end{array}$ & $\begin{array}{l}40 \mathrm{~mm} \\
(232.40 \mathrm{~g})\end{array}$ & $\begin{array}{l}60 \mathrm{~mm} \\
(373.19 \mathrm{~g})\end{array}$ & $\begin{array}{l}40 \mathrm{~mm} \\
(234.10 \mathrm{~g})\end{array}$ \\
\hline Volume of water & \multirow{2}{*}{\multicolumn{5}{|c|}{$\begin{array}{l}2.5 \mathrm{~L} \\
\text { Reclaimed water (I city) Tan water (G citv) }\end{array}$}} \\
\hline Source of water & & & & & \\
\hline $\begin{array}{l}\text { Measurement } \\
\text { paramenters }\end{array}$ & \multicolumn{5}{|c|}{$\begin{array}{l}\text { Temperature, } \mathrm{pH}, \mathrm{DO} \text {, Hardness, Alkalinity, Chlorine, TDS, } \mathrm{NH}_{4}^{+} \text {, } \\
\mathrm{PO}_{4}{ }^{3-}, \mathrm{SO}_{4}^{2-}, \mathrm{Cl}^{-}\end{array}$} \\
\hline
\end{tabular}

The installed device for injecting the experimental water was run for a total of 60 days. As there was a risk of the occurrence of water quality changes in the experimental water during long-term storage, the reclaimed water was stored in the refrigerator $\left(3^{\circ} \mathrm{C}\right)$. As such, there were minimal changes in the water quality. The replacement period of the experimental water was 1 week.

Measurement of corrosion rate. In this study, the weight loss method was utilized for the measurement of the corrosion rate. Before the start of the experiment, the weight of each specimen was measured up to the second decimal place, and every time the experimental water was replaced, the corrosion products of the carbon steel and zinc specimens were removed, after which the specimens were weighed. The corrosion products were removed according to the method of removing corrosion products specified in KS D ISO 8407:2014 (Table 4). Finally, the corrosion rate was calculated using equation (1), in $\mathrm{mdd}(\mathrm{mm} / \mathrm{yr})$ unit converts.

Table 4. Chemical Cleaning Method of Corrosion Product

\begin{tabular}{ccccc}
\hline Material & Chemical & Time & Temperature & Remark \\
\hline Iron and steel & $\begin{array}{c}1000 \mathrm{~mL} \mathrm{HCl}+20 \\
\mathrm{~g} \mathrm{Sb}_{2} \mathrm{O}_{3}+50 \mathrm{~g} \\
\mathrm{SnCl}_{2}\end{array}$ & $1 \sim 25 \mathrm{~min}$ & $20 \sim 25{ }^{\circ} \mathrm{C}$ & $\begin{array}{c}\text { Followed by strong } \\
\text { agitation or light scrub }\end{array}$ \\
$\begin{array}{c}\text { Zinc and } \\
\text { zinc alloy }\end{array}$ & $\begin{array}{c}100 \mathrm{~g} \mathrm{Glycine}+ \\
\text { mL distilled } \\
\text { water }\end{array}$ & $1 \sim 10 \mathrm{~min}$ & $20 \sim 25{ }^{\circ} \mathrm{C}$ & $\begin{array}{c}\text { Followed by light } \\
\text { scrub }\end{array}$ \\
\hline
\end{tabular}

$$
\mathrm{mm} / \mathrm{yr}=87.6 \times \mathrm{W} /(\mathrm{D} \times \mathrm{A} \times \mathrm{T})
$$

Wherein $\mathrm{W}$ is the weight loss $(\mathrm{mg})$; $\mathrm{D}$, the density $\left(\mathrm{g} / \mathrm{cm}^{3}\right)$; A, the area $\left(\mathrm{in}^{2}\right)$; and $\mathrm{T}$, the time (hours).

Comparison of the corrosion rates of tap and reclaimed water. According to the study conducted by Kim (2012), reclaimed water has a stronger corrosive characteristic compared to tap water. Furthermore, in this study, the SA efficiency and corrosion behavior of the reclaimed water were compared with those of the tap water. Therefore, analysis can be done by comparing the corrosion rates of experimental device nos. 3 and 5 under the same conditions, except for the experimental water.

Analysis of corrosive index (KRWI). To evaluate the corrosiveness of the water supplied, the corrosive index was used. According to the progress of corrosion, the corrosive environment inside the pipe changes. Therefore, observation was done to 
determine if the corrosion index varies according to the degree of corrosion in the water passing through the pipe. As for the time for replacing the experimental water, experimental water was collected to measure the corrosion acceleration and inhibitory factors. Then KRWI was calculated using equation (2), and the tendency of corrosive index change was observed utilizing the resulting value.

$$
\begin{array}{r}
K R W I=\left[\left(2 \times \frac{\sum_{i=1}^{n 1} W_{\infty i n_{i}} / W_{\infty \infty_{i}}+\sum_{i=1}^{n 2} W_{\infty i_{i}} / W_{\infty \alpha c_{i}}}{n 1+n 2}\right)\right. \\
\left.+\left(\frac{\sum_{i=1}^{n 1} W_{\infty n_{i}} / W_{\infty i_{i}}+\sum_{i=1}^{n 2} W_{\infty i_{i}} / W_{\infty c_{i}}}{n 3+n 4}\right)\right] / 3
\end{array}
$$

Wherein, Wqo is the optimal water quality for corrosion inhibition; Wqin, the measured corrosion that inhibits the water quality; Wqac, the measured corrosion that promotes the water quality; $\mathrm{n} 1$, the number of items of the corrosion inhibition factor; $\mathrm{n} 2$, the number of items of the corrosion acceleration factor; $\mathrm{n} 3$ is the number of items of the added corrosion inhibition factor, and $\mathrm{n} 4$ the number of items of the added corrosion acceleration factor.

\subsection{Experiment Result}

2.4.1 Comparison of the Corrosion Rates of the Water Pipes based on Whether the SA Method was Applied or Not: According to the graph shown in Fig. 13-15 of the corrosion rates of the equipment to which the SA method was applied [specimen no. 2 (zinc, $20 \mathrm{~mm}$ ), specimen no. 3 (zinc, $40 \mathrm{~mm}$ ), and specimen no. 4 (zinc, $60 \mathrm{~mm}$ )], the initial corrosion rate was formed in the order of specimen no. $2>$ no. $3>$ no. 4 . This indicates that the initial corrosion effect is excellent when more SA metal is applied. After two weeks, however, the corrosion rate decreased under all the conditions, and finally, the corrosion rates converged towards 0 mdd after 50 days in the case of specimen no. 2, and after 35 days in the case of specimen no. 3. Significant amounts of corrosion products (rust) were generated in carbon steel 1 of specimen no. 1, to which the SA method was not applied.

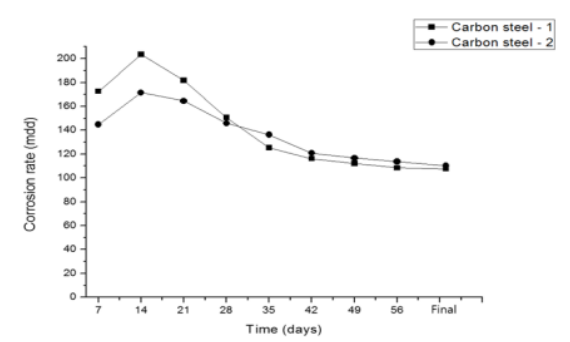

(NO.1)

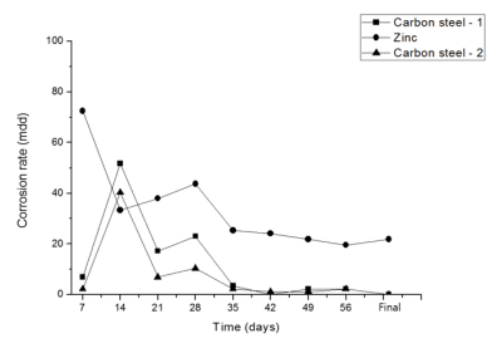

(No.3)

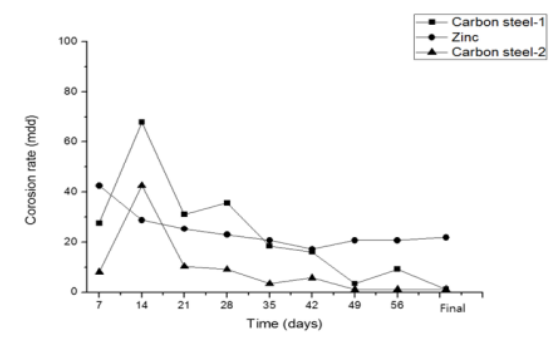

(NO.2)

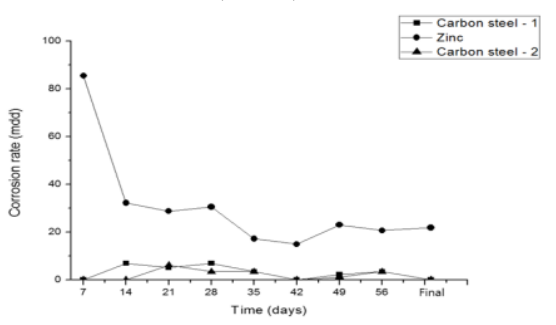

(No.4)

Figure 3. Trend Graph of Specimens 
2.4.2 Comparison of the Corrosion Rates of Reclaimed and Tap Water: In a previous research, it was found that reclaimed water is more corrosive than tap water. The corrosion behavior when the SA method was applied, however, revealed other aspects of corrosion, unlike in the unprotected condition. For specimen no. 3 (reclaimed water) and no. 5 (tap water), equal conditions were set, except for the experimental water, and then the corrosion rates were measured. The corrosion rate trends, as shown in Fig. 16, looked similar, but their values were different. For specimen no. 3, the corrosion rate trend was recorded as under $10 \mathrm{mdd}$, and the maximum corrosion rate was confirmed to be $51.77 \mathrm{mdd}$. On the other hand, specimen no. 5, which used tap water, showed a 70-80 mdd corrosion rate trend, and its maximum corrosion rate was shown to be $150.72 \mathrm{mdd}$. The results of the average-corrosion-rate analysis confirmed that the corrosion rate of specimen no. 5 (95.68 mdd) was about tenfold faster than that of specimen no. 3 (9.65 mdd).

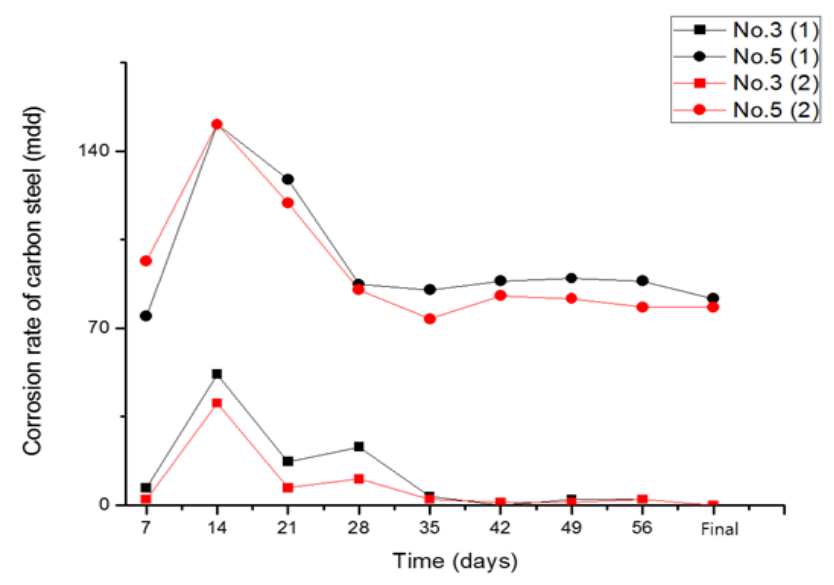

Figure 4. Comparison of Corrosion Rate (No.3 vs No.5)

2.4.3 Analysis of corrosive index (KRWI): As corrosion progresses and worsens, the water quality was analyzed using the water quality analysis data and the KRWI equation, to determine if the corrosion characteristics of the reclaimed water changed. As a result of the analysis, the value of KRWI confirmed that there were no major changes in the four experimental equipment utilizing reclaimed water, as shown in Fig. 5. These results are consistent with those of the previous research on KRWI development (Lee et al., 2011) showing no significant variation in the change of the corrosive index according to the corrosion progress. The reason that there was no change in the corrosion index is that the quality factors affecting the corrosion characteristics did not change significantly despite the fact that degradation of the sanitary water quality occurred due to the corrosion progress. In particular, if the measured water quality value is smaller than the optimal water quality value, such value will hardly influence the results of the corrosion index variation. 


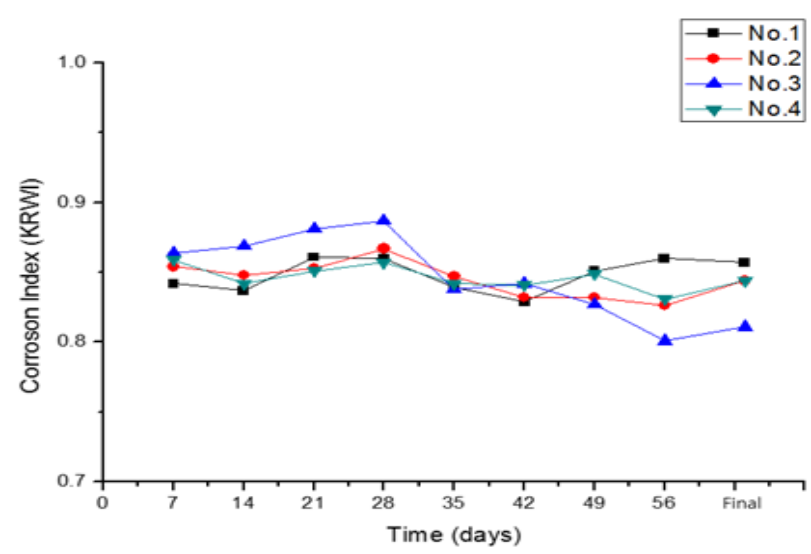

Figure 5. Comparison of KRWI Trend

\section{Conclusion}

High-purity zinc was selected as an SA metal for the application of the SA method to a reclaimed-water pipe. To analyze the corrosion rate change trend corresponding to the SA metal amount, four equipment were used, each with a different experiment condition. Basically, one equipment (no. 1) had no SA metal, meaning the SA method was not applied to it. For the three other equipment (nos. 2-4), the SA method was applied to them, and the amount of SA metal used was different for each device.

For the reclaimed-water pipes to which SA metal (zinc) was applied, the case where $20 \mathrm{~mm}$ SA metal was applied (specimen no. 2) recorded a maximum corrosion rate of $67.88 \mathrm{mdd}$, and the corrosion rates converged towards 0 mdd after 50 days. In the case with $40 \mathrm{~mm}$ SA metal applied (specimen no. 3 ), the corrosion rate was stabilized (0 mdd) 35 days later, and the maximum corrosion rate was recorded at $51.77 \mathrm{mdd}$. In the case where the highest amount $(60 \mathrm{~mm})$ of SA metal was applied (specimen no. 4), the maximum corrosion rate was $6.21 \mathrm{mdd}$, but almost all the corrosion rates were shown to be approximately $0 \mathrm{mdd}$. The corrosion rate of the reclaimed-water pipe to which the SA method was not applied showed a value of up to $203.64 \mathrm{mdd}$ and at least $107.54 \mathrm{mdd}$. Thus, it was concluded that if the SA method is applied to a reclaimed-water pipe, it will show an anticorrosion effect. Also, by increasing the amount of SA metal used, the initial anticorrosion effect can be made higher. In addition, it was found in this study that placing an SA metal at the pipe entrance in the flow direction of the water can yield a higher anticorrosion effect than when an SA metal is not placed at the pipe entrance.

The effect that was obtained when the G City tap water was used was not large compared to the effect that was obtained when reclaimed water was used. The reason for this is that a difference in the consumption of the SA metal occurs depending on the conductivity of the experimental water used. Accordingly, the SA efficiency was affected. In other words, the efficiency of the SA method increases in a pipeline where highconductivity water flows.

The corrosive-index (KRWI) trend was not large regardless of the flow time and the degree of corrosion. This means that the quality factors affecting the corrosion characteristics are not significantly changed despite the occurrence of sanitary water quality degradation due to corrosion progress.

\section{Acknowledgements}

This study was supported by the main project "Development of Water Distribution Technology in Micro-grid" of the Korea Institute of Civil Engineering and Building Technology. 


\section{References}

[1] S. W. Kang, J. Y. Lee, H. D. Lee, J. E. Kim and P. J. Kwak, "Characteristics of Corrosion and Water Quality in Simulated Reclaimed Water Distribution Pipelines, Journal of Korean Society of Environmental Engineers, (2012), pp.473-479.

[2] H. D. Lee, G. E. Kim, P. J. Kwak, J. H. Park, M. S. Kong, S. W. Kang and J. Y. Lee, "Corrosion Indices Evaluation Reclaimed Water and Development of KRWI (Korea Reclaimed Water Index)", Journal of Korean Society of Water Science and Technology, (2012), pp.17-25.

[3] I. H. Choi, "Korea Water Reuse Situation and Policy Direction: By 2020", Water Journal, (2002), pp.4447.

[4] H. Michael, C. Timothy and V. E. Rudi, "Theoretical Study of the Water Exchange Reaction on Divalent Zinc Ion using Density Functional Theory”, Journal of Molecular Modeling, (1996), pp.354-357.

\section{Authors}

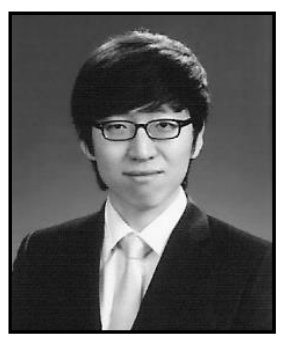

Myeongsik Kong

ACADEMIC BACKGROUND:

Aug 2013, Korea University of Science and Technology, MS in Construction and Environment Engineering

Feb 2010, University of Seoul, BD in Environmental Engineering

PROFESSIONAL EXPERIENCE:

Sep 2013 , Korea Institute of Civil Engineering and Building Technology, Researcher, Environment and Plant Engineering Research Institute

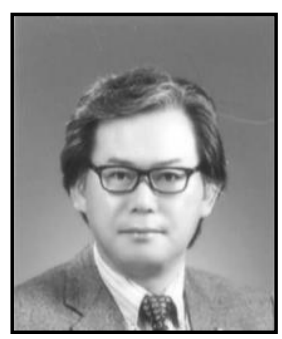

\section{Hyundong Lee}

ACADEMIC BACKGROUND:

Oct 1993, Kyoto University, Post-Ph.D in Environmental Engineering. Aug 1991, Hanyang University, Ph.D in Civil and Environmental Engineering

Feb 1987, Hanyang University, MS in Civil and Environmental Engineering

PROFESSIONAL EXPERIENCE:

Sep 2007 , Korea University of Science \& Technology, Professor with Department of Construction \& Environment Engineering

Dec $2004 \sim$ Dec 2005, The University of Iowa, Visiting Professor with Department of Civil \& Environmental Engineering

Jul 1987 , Korea Institute of Civil Engineering and Building Technology, Senior Research Fellow, Environment and Plant Engineering Research Institute

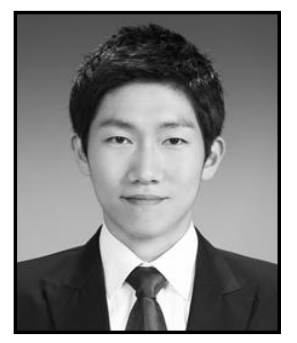

\section{Joonhyung, Lee}

ACADEMIC BACKGROUND:

Feb 2015, Korea University of Science and Technology, MS in Construction and Environment Engineering

Feb 2013, Hanyang University, BD in Civil and Environmental Engineering

\section{PROFESSIONAL EXPERIENCE:}

Mar 2015 , Korea Institute for Advancement of Technology, Researcher, Regional Policy Planning Team 